\title{
THE DISSOCIATIVE IONIZATION OF NITROUS OXIDE. A COMPARISON BETWEEN ELECTROIONIZATION AND HeI AND NeI PHOTOIONIZATION
}

\author{
R. LOCHT, G. CAPRACE and J. MOMIGNY \\ Département de Chimie Générale et de Chimie-Physique, Institut de Chimie, Bâtiment B.6, Université de Liège, Sart-Tilman par B-4000 \\ Liège 1, Belgium
}

\begin{abstract}
The photoelectron spectrum of $\mathrm{N}_{2} \mathrm{O}$ and the kinetic energy distributions of $\mathrm{NO}^{+}, \mathrm{N}_{2}^{+}, \mathrm{O}^{+}$and $\mathrm{N}^{+}$have been recorded with the $\mathrm{HeI}$ and $\mathrm{NeI}$ resonance lines. At $21.22 \mathrm{eV}$, the distributions are similar to those observed by electroionization at comparable energy. The NeI resonance line produces $\mathrm{O}^{+}$and $\mathrm{NO}^{+}$ions. Their respective kinetic energy distributions are related to the change induced in the $\mathrm{N}_{2} \mathrm{O}^{+}\left(\tilde{\mathrm{A}}^{2} \Sigma^{+}\right)$photoelectron band excited by the NeI resonance lines.
\end{abstract}

We recently reported [1,2] on the dissociative electroionization of $\mathrm{N}_{2} \mathrm{O}$. The four dissociation channels producing $\mathrm{NO}^{+}, \mathrm{N}_{2}^{+}, \mathrm{O}^{+}$and $\mathrm{N}^{+}$were extensively discussed on the basis of the kinetic energy distribution spectra and the ionization efficiency curves of the mass-selected fragment ions.

The main difficulty in interpreting the electroionization results is the superposition of autoionization on the direct ionization phenomena. The electroionization threshold law and the lack of electron energy resolution are additional disadvantages.

To avoid autoionization, the most convenient technique is the use of a monochromatic light source, the wavelength of which is non-resonant with an autoionizing state. In most cases, the HeI resonance line at 58.43 $\mathrm{nm}(21.22 \mathrm{eV})$ is non-resonant with autoionization [3]. In principle, the resonance lines of the other gases can also be used. However, several investigations [4] showed these lines to produce direct ionization and autoionization as well. The photoelectron spectra recorded with these lines can differ markedly from those excited by the HeI resonance line.

The aim of this letter is to describe the kinetic energy spectra of the four fragment ions obtained by exciting the $\mathrm{N}_{2} \mathrm{O}$ molecule by the $\mathrm{HeI}$ and $\mathrm{NeI}$ resonance lines at $58.43 \mathrm{~nm}$ and $73.59-74.37 \mathrm{~nm}$, respectively.

The experimental apparatus used in the present work will be described in detail elsewhere [5]. The main features only are mentioned here. The light, produced by a discharge in the abovementioned rare gases, is led into an ion chamber through a capillary. The photoions are extracted by a $0-300 \mathrm{mV} \mathrm{cm}^{-1} \mathrm{draw}$-out field. After leaving the ion source and before entering a quadrupole mass filter, the ions are energy analyzed by means of a retarding lens. The retarding potential $V_{r}$ is scanned by applying a voltage ramp to the retarding lens. The first derivative of the retarding potential curve of the $\mathrm{Ar}^{+}$ions has a fwhm of about $80 \mathrm{meV}$.

The photoelectrons, flying in the opposite direction to the photoions, can be energy analyzed in a retarding potential-type analyzer with a differential output [6]. The resolution as measured in the photoelectron spectrum of Ar has been limited to $40-50 \mathrm{meV}$.

Both the ions and electrons are detected by means of conventional $\mathrm{Cu}$-Be electron multipliers followed by counting electronics. Both signals are collected and stored in a minicomputer for further handling and recording.

The intensity ratios measured in the mass spectrum of $\mathrm{N}_{2} \mathrm{O}$, as obtained with the HeI resonance line, are $1.00\left(\mathrm{~N}_{2} \mathrm{O}^{+}\right): 0.50\left(\mathrm{NO}^{+}\right): 0.13\left(\mathrm{~N}_{2}^{+}\right): 0.2\left(\mathrm{O}^{+}\right): 0.4\left(\mathrm{~N}^{+}\right)$. These values have to be compared with $1.00: 0.54: 0.12$ : 0.2 : 0.2 obtained by Brehm et al. [7] with the same radiation. Figs. 1 and 2 show the ion energy distribution spectra of $\mathrm{NO}^{+}-\mathrm{N}_{2}^{+}$and $\mathrm{O}^{+}-\mathrm{N}^{+}$observed under the same conditions. Compared to the parent ion, used as an internal standard for the ion energy scale, all the fragment ions exhibit a high-energy tail. No structure is observed. All distributions show an important thermal energy peak. By electroionization [1,2], the same features 
have been observed previously for the same ions at comparable electron energies.

Fig. 1. First derivative of the retarding potential curves for $\mathrm{NO}^{+}$and $\mathrm{N}_{2}^{+}$ions, observed with the HeI resonance line at $58.4 \mathrm{~nm}$.

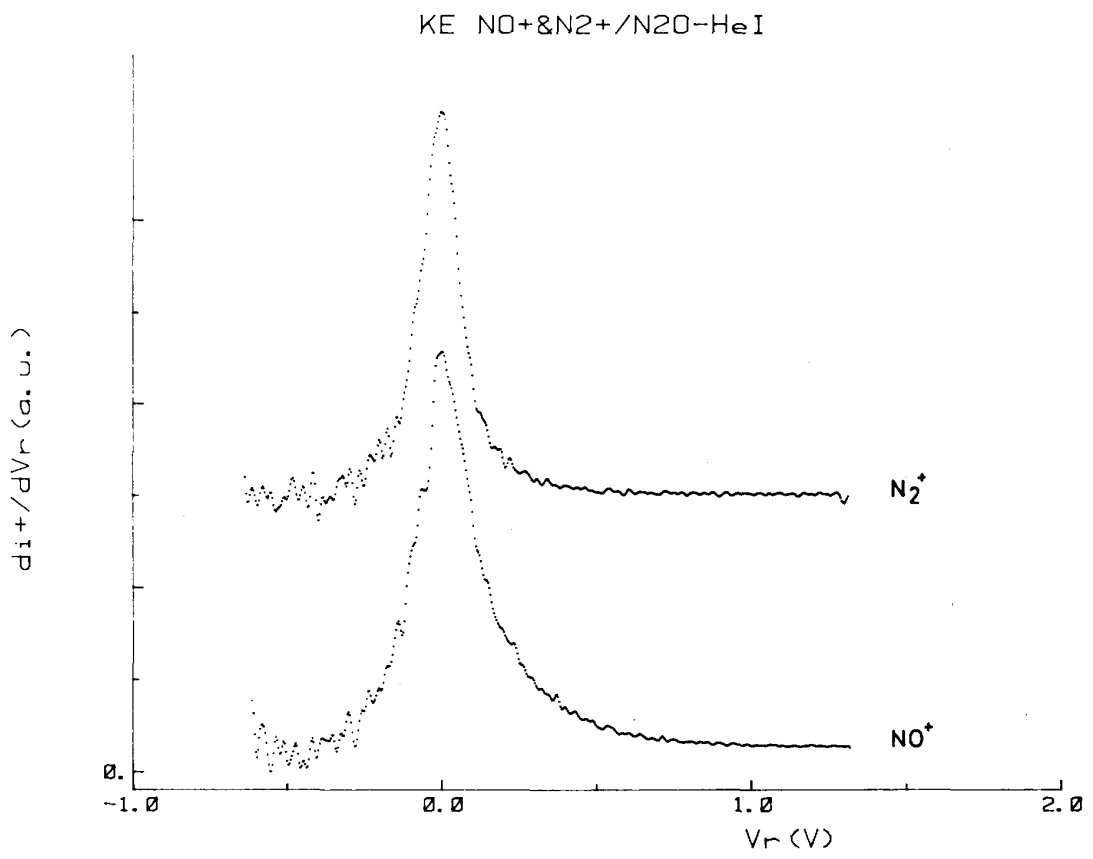

Fig. 2. First derivative of the retarding potential curves for $\mathrm{O}^{+}$and $\mathrm{N}^{+}$ions, observed the HeI resonance line at $58.4 \mathrm{~nm}$.

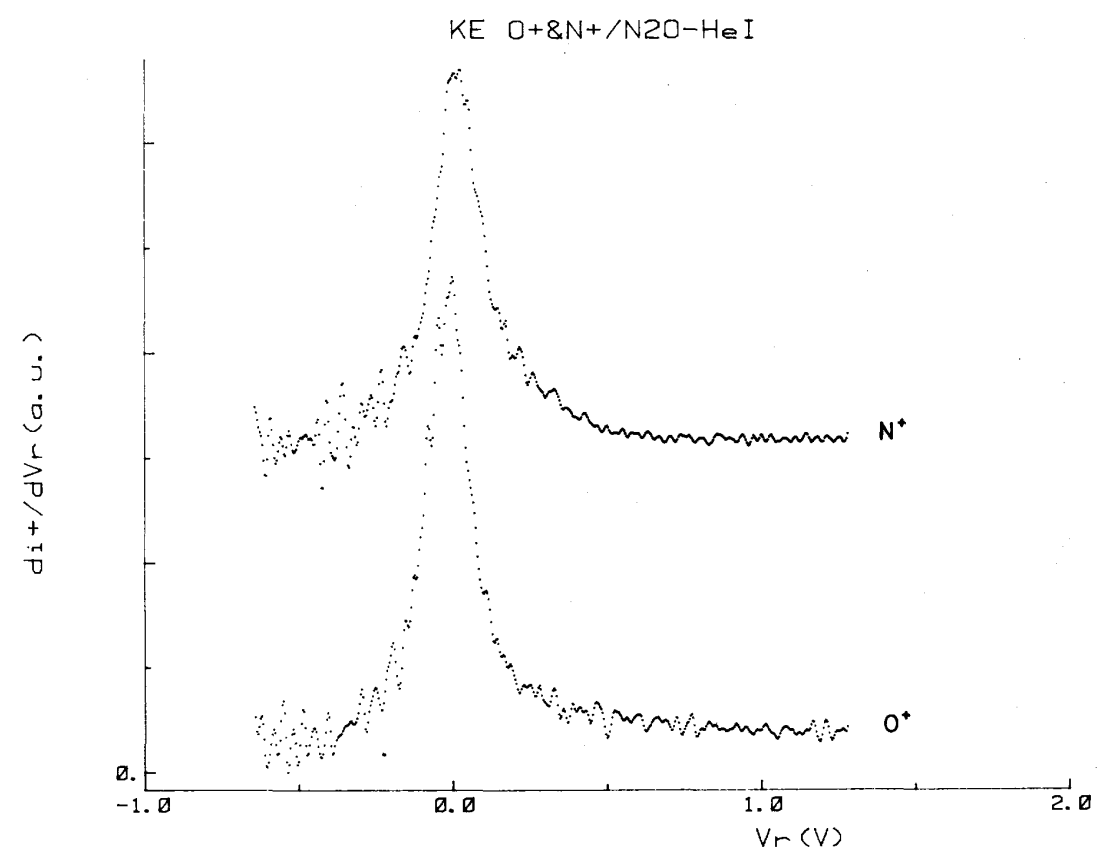


Fig. 3. First derivative of the retarding potential curves for $\mathrm{NO}^{+}$and $\mathrm{O}^{+}$ions observed with the NeI resonance line at 73.59-74.37 $\mathrm{nm}$.

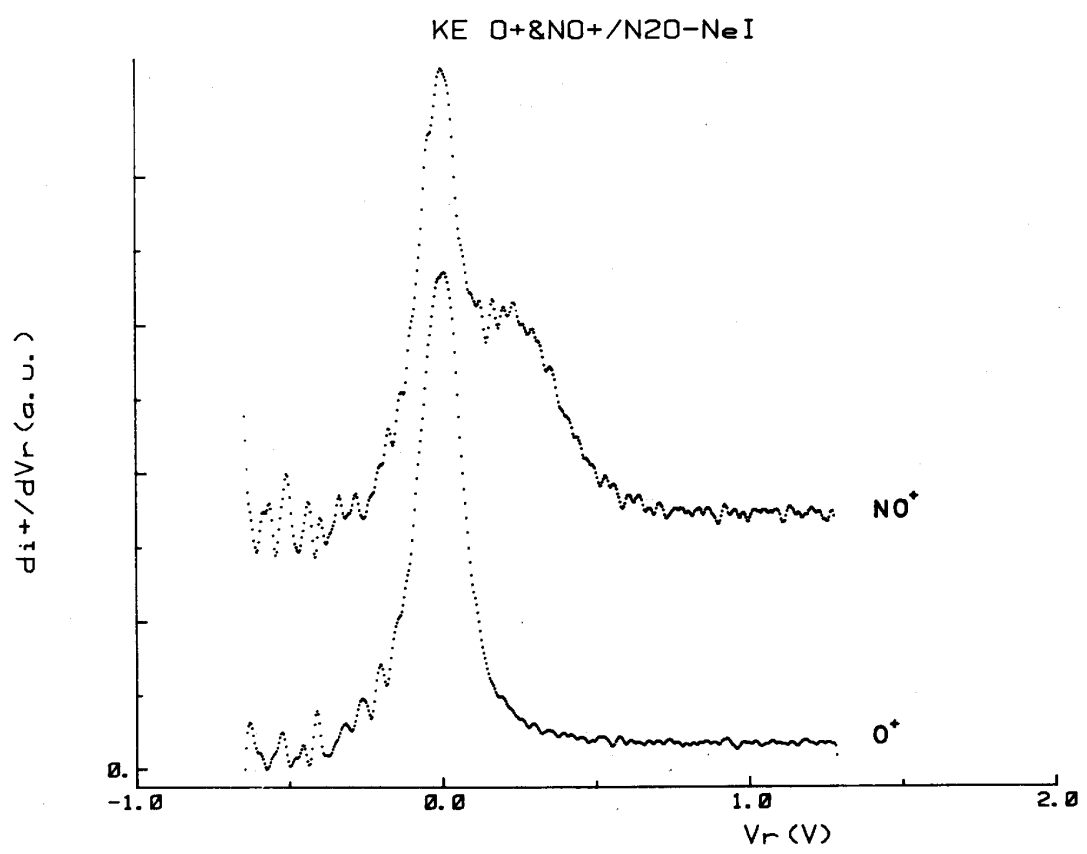

As has been shown in both photoionization [7-9] andelectroionization [1,2], the distributions observed at $21.22 \mathrm{eV}$ result from the added contributions of the predissociationof the $\widetilde{\mathrm{A}}^{2} \Sigma^{+}, \widetilde{\mathrm{B}}^{2} \Pi$ and/or $\widetilde{\mathrm{C}}^{2} \Sigma^{+}$states of $\mathrm{N}_{2} \mathrm{O}^{+}$. The predissociationof the higher vibrational levels of the $\mathrm{N}_{2} \mathrm{O}^{+}\left(\widetilde{\mathrm{X}}^{2} \Pi\right)$ state, observed by electron impact and resonant photoionization, is ruled out in fixed-wavelength photoionization using the HeI resonance line [7]. These vibrational levels are known experimentally to be populated by autoionization only [10].

From these considerations, it follows that the kinetic energy distributions measured by HeI photoionization are expected to lead to a clearer situation than by electron impact. For both $\mathrm{O}^{+}$and $\mathrm{N}^{+}$, thermal ions were observed and at least partially ascribed to the decomposition of the $\mathrm{N}_{2} \mathrm{O}^{+}\left(\widetilde{\mathrm{X}}^{2} \Pi\right)$ state [1,2].

First, for the $\mathrm{O}^{+}$ions produced by electroionization [2], the kinetic-energy versus appearance-energy diagram shows thermal ions to be formed at the expense of the $\mathrm{N}_{2} \mathrm{O}^{+}\left(\widetilde{\mathrm{X}}^{2} \Pi\right)$ state. On the other hand, the HeI kinetic energy spectrum of $\mathrm{O}^{+}$shows a thermal $\mathrm{O}^{+}$ion also. In the energy range of this radiation, at least twc dissociation processes are energetically allowed, i.e.

$$
\begin{aligned}
& \mathrm{N}_{2} \mathrm{O}^{+}\left(\widetilde{\mathrm{B}}{ }^{2} \Pi\right) \rightarrow \mathrm{N}_{2}\left(\mathrm{X}^{2} \Sigma_{\mathrm{g}}^{+}, v=2 \text { or } 3\right) \\
& \mathrm{O}^{+}\left({ }^{2} \mathrm{D}\right)+\mathrm{KE}=0
\end{aligned}
$$

at $19.188 / 19.470 \mathrm{eV}$,

$$
\begin{aligned}
& \mathrm{N}_{2} \mathrm{O}^{+}\left(\tilde{\mathrm{A}}^{2} \Sigma^{+}\right) \rightarrow \mathrm{N}_{2}\left(\mathrm{X}^{2} \Sigma_{\mathrm{g}}^{+}, v=5\right) \\
& +\mathrm{O}^{+}\left({ }^{4} \mathrm{~S}\right)+\mathrm{KE}=0
\end{aligned}
$$

at $16.700 \mathrm{eV}$. Only process (1) could be detected by electroionization [2].

Secondly, as noticed earlier [1], one dissociation process giving rise to $\mathrm{NO}^{+}$ions, i.e.

$$
\begin{aligned}
& \mathrm{N}_{2} \mathrm{O}^{+}\left(\tilde{\mathrm{A}}^{2} \Sigma^{+}\right) \rightarrow \mathrm{NO}^{+}\left(\mathrm{X}^{1} \Sigma^{+}, v=0\right) \\
& +\mathrm{N}\left({ }^{2} \mathrm{D}\right)+\mathrm{KE}=0
\end{aligned}
$$

at $16.577 \mathrm{eV}$, could not be deduced unambiguously from the kinetic-energy versus appearance-energy diagram. 
However, this reaction is energetically allowed and is produced by photodissociation of $\mathrm{N}_{2} \mathrm{O}^{+}$ion beams [11], and was proposed by Brehm et al. [7] or the basis of photoion-photoelectron coincidence experiments.

Closer to the threshold of processes (2) and (3), and therefore more selective, is the use of the NeI resonance lines at $16.85-16.67 \mathrm{eV}$. Only the $\tilde{\mathrm{X}}^{2} \Pi$ and the $\tilde{\mathrm{A}}^{2} \Sigma^{+}$states of $\mathrm{N}_{2} \mathrm{O}^{+}$could be excited. These states have been shown to procedure $\mathrm{O}^{+}$and $\mathrm{NO}^{+}$fragments only $[7,10]$.

At these energies, the intensity ratios in the mass spectrum are $1.00\left(\mathrm{~N}_{2} \mathrm{O}^{+}\right): 0.10\left(\mathrm{NO}^{+}\right): 0.07\left(\mathrm{O}^{+}\right)$. Fig. 3 shows the kinetic energy distribution of $\mathrm{NO}^{+}$and $\mathrm{O}^{+}$as observed with the NeI resonance lines. For the $\mathrm{O}^{+}$ion, the shape of the distribution is comparable with the spectrum observed at $21.22 \mathrm{eV}$, but with a shorter highenergy tail. A thermal energy peak is still observed. On the contrary, the $\mathrm{NO}^{+}$ion energy spectrum looks quite different to the distribution observed with HeI. Two distinct components are found, i.e. a thermal peak and a high-energy distribution with a maximum near $200 \mathrm{meV}$ and extending to about $700 \mathrm{meV}$. Noteworthy is that the shape of this distribution differs significantly from the $\mathrm{NO}^{+}$ion energy spectrum recorded with 16.0 and 17.0 eV electrons [1].

By using NeI radiation instead of the HeI resonance line, changes could occur in the photoelectron spectrum which could account for the differences observed in the ion energy distributions. In the particular case of $\mathrm{N}_{2} \mathrm{O}$, it has to be noted that the $74.372 \mathrm{~nm}$ line, produced in the Ne discharge, is nearly resonant with 74.293 $\mathrm{nm}$ autoionization peak observed in the photo-ionization efficiency curves of $\mathrm{O}^{+}, \mathrm{NO}^{+}$and $\mathrm{N}_{2} \mathrm{O}^{+}$with less intensity $[8,12]$. As mentioned earlier, autoionization could induce drastic changes in the photoelectron spectra [4].

The HeI and NeI photoelectron spectra of $\tilde{\mathrm{X}}^{2} \Pi$ and $\tilde{\mathrm{A}}^{2} \Sigma^{+}$states of $\mathrm{N}_{2} \mathrm{O}^{+}$have been recorded. Important changes in relative intensities are observed in both photoelectron bands. The deconvoluted photoelectron spectrum of the $\mathrm{N}_{2} \mathrm{O}^{+}\left(\tilde{\mathrm{A}}^{2} \Sigma^{+}\right)$state, as obtained with the NeI resonance lines, is shown in fig. 4. The equivalent resolution, as measured by the fwhm of the $\tilde{\mathrm{A}}^{2} \Sigma^{+}(0,0,0)$ peak, is $13 \mathrm{meV}$ [13]. Table 1 displays the relative intensities corrected for the electron analyzer transmission, in both the HeI and NeI spectra. For comparison, the values measured previously by Dehmer et al. [12] and Frey et al. [9] are reproduced. The doublet $\mathrm{Kr}^{+}\left({ }^{2} \mathrm{P}_{3 / 2}{ }^{2} \mathrm{P}_{1 / 2}\right)$ is used for calibration of the electron energy scale. The ionization potentials deduced from these spectra are listed in the last column of table 1.

Table 1 : Comparison of the relative intensities for the $\mathrm{N}_{2} \mathrm{O}^{+} \tilde{A}^{2} \Sigma^{+}\left(v_{1}, v_{2}, v_{3}\right)$ transitions obtained with HeI and $\mathrm{NeI}$

\begin{tabular}{|c|c|c|c|c|c|c|}
\hline \multirow[t]{2}{*}{$v_{1}, v_{2}, v_{3}[12]$} & \multicolumn{2}{|c|}{ HeI } & \multirow{2}{*}{$\begin{array}{c}\text { TPES } \\
\text { [9] }\end{array}$} & \multirow{2}{*}{$\begin{array}{c}\text { NeI } \\
\text { this work }\end{array}$} & \multirow{2}{*}{$\begin{array}{c}\text { Ratios } \\
\text { NeI/[12] }\end{array}$} & \multirow[t]{2}{*}{$\operatorname{IP}(e V)$} \\
\hline & ref.[12] & this work & & & & \\
\hline $0,0,0$ & 100 & 100 & 100 & 100 & 1 & 16.387 \\
\hline $0,1,0$ & $\approx 2.1$ & $<5^{\text {a) }}$ & - & 30 & $\approx 15$ & 16.472 \\
\hline $1,0,0$ & 21.7 & $<28^{\text {a) }}$ & 39.5 & 23 & $\approx 1$ & 16.563 \\
\hline $1,1,0(?)$ & (1.1) & - & - & 30 & $\approx 30$ & 16.636 \\
\hline $0,0,1$ & 8.5 & $<10^{\mathrm{a})}$ & 10.8 & 17 & $\approx 2$ & 16.665 \\
\hline $2,0,0$ & 0.5 & $<2^{\mathrm{a})}$ & 7.3 & 7.6 & $\approx 15$ & 16.722 \\
\hline $0,1,1$ & 0.1 & - & - & 15 & $\approx 150$ & 16.764 \\
\hline $1,0,1$ & 1.0 & - & - & & & \\
\hline $3,0,0$ & 0.1 & - & - & & & \\
\hline $0,0,2$ & 0.5 & - & - & & & \\
\hline
\end{tabular}

The assignments proposed by Dehmer et al. [12] have been used to interpret the spectrum shown in fig. 4. Two peaks could not be assigned, i.e. those at 16.444 and $16.787 \mathrm{eV}$. This last feature was observed in previous spectra of the $\mathrm{N}_{2} \mathrm{O}^{+}\left(\tilde{\mathrm{A}}^{2} \Sigma^{+}\right)$band [12]. 
Fig. 4. Deconvoluted photoelectron spectrum of the $\mathrm{N}_{2} \mathrm{O}^{+}\left(\tilde{A}^{2} \Sigma^{+}\right)$state recorded with the NeI resonance line.

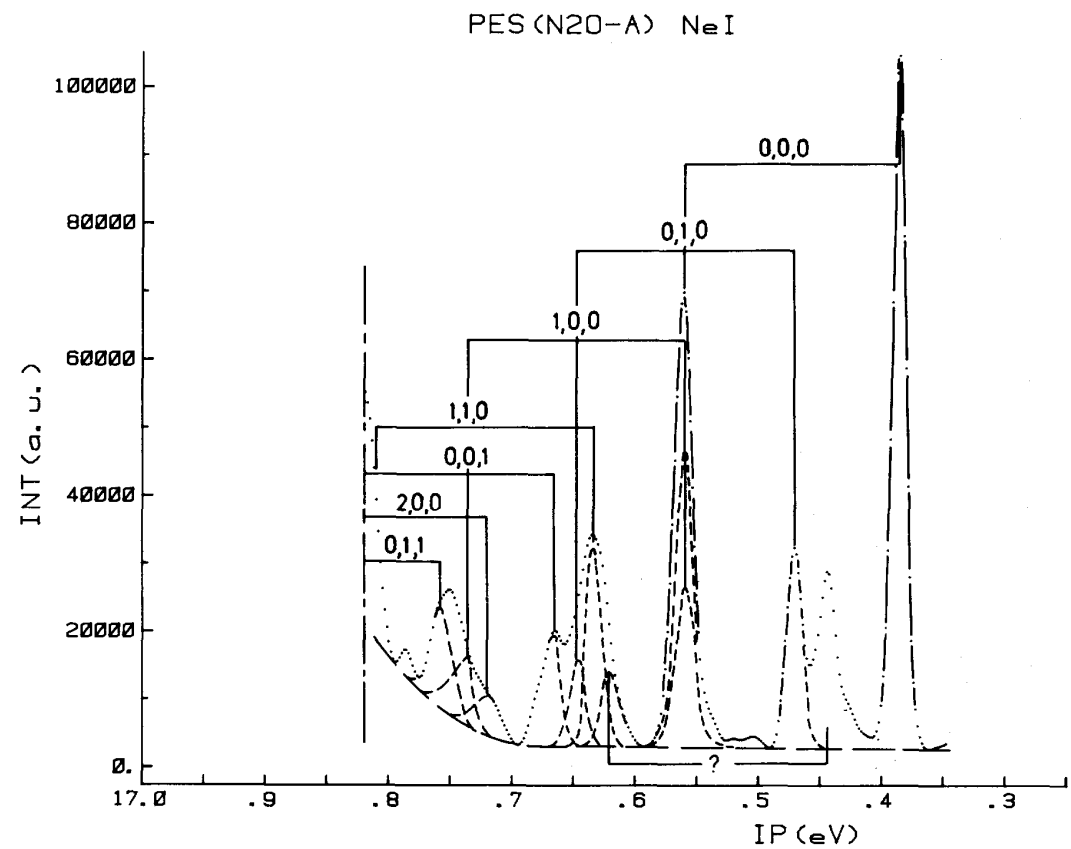

With 16.85-16.67 eV radiation, $\mathrm{O}^{+}$ions are still produced with thermal or nearly thermal energy. Only process (2) can be invoked. This process has not been observed by electroionization [2], where only $\mathrm{N}_{2} \mathrm{O}^{+}\left(\tilde{\mathrm{A}}^{2} \Sigma^{+}\right)$ $\rightarrow \mathrm{N}_{2}\left(\mathrm{X}^{1} \Sigma_{\mathrm{g}}{ }^{+}, v=2-3\right)+\mathrm{O}^{+}\left({ }^{4} \mathrm{~S}\right)+\mathrm{KE} \geq 0.5 \mathrm{eV}$ is compatible with the experimental data. The thermo dynamic threshold for the dissociation path (2) is close to the energy of the $(2,0,0)$ level of the $\tilde{\mathrm{A}}^{2} \Sigma^{+}$state. As shown in table 1 , the relative intensity of this transition is enhanced by a factor of 15 . This observation could account for the intensity of the thermal energy peak. The high-energy tail of the $\mathrm{O}^{+}$ion energy distribution, extending up to 400-500 meV, can be ascribed to the partition of the excess energy with respect to $15.291 \mathrm{eV}$ between kinetic energy of the fragments and the vibrational energy of $\mathrm{N}_{2}\left(\mathrm{X}^{1} \Sigma_{\mathrm{g}}{ }^{+}, v=4-2\right)$.

With the NeI resonance lines at $16.67-16.85 \mathrm{eV}$, the $\mathrm{NO}^{+}$ions can be produced through the predissociation of $\mathrm{N}_{2} \mathrm{O}^{+}\left(\tilde{\mathrm{A}}^{2} \Sigma^{+}\right)$vibrational levels lying above $v=0,0,0$ [7] and leading to (i) the abovementioned process (3) and/or (ii) $\mathrm{NO}^{+}\left(\mathrm{X}^{1} \Sigma^{+}, v\right)+\mathrm{N}\left({ }^{4} \mathrm{~S}\right)+\mathrm{KE} \geq 0$, for which the lowest threshold is at $14.194 \mathrm{eV}$.

For the first process, the thermodynamic onset is calculated at $16.577 \mathrm{eV}$. This dissociation path is opened at the $\tilde{\mathrm{A}}^{2} \Sigma^{+}(1,1,0)$ level measured at $16.636 \mathrm{eV}$, producing $\mathrm{NO}^{+}$ions carrying $19 \mathrm{meV}$ kinetic energy. Brehm et al. [7] assigned the low-energy $\mathrm{NO}^{+}$ions, in coincidence with $16.61 \mathrm{eV}$ electrons, to this process and state "this new channel makes a small but detectable contribution". It has to be pointed out that in the NeI photoelectron spectrum the relative intensity of the $\tilde{\mathrm{A}}^{2} \Sigma^{+}(1,1,0)$ level is increased by about 30 . This observation could a least partially account for the fairly intense low-energy peak in the $\mathrm{NO}^{+}$ion energy distribution in fig. 3 . Another dissociation channel would at least formally be allowed at $16.665 \mathrm{eV}$, i.e. at the $\tilde{\mathrm{A}}^{2} \sum^{+}(0,0,1)$ level, and produce thermal $\mathrm{NO}^{+}$ions, i.e. $\mathrm{NO}^{+}\left(\mathrm{X}^{1} \Sigma^{+}, v=9\right)+\mathrm{N}\left({ }^{4} \mathrm{~S}\right)$, which has its calculated threshold at $16.657 \mathrm{eV}$, using the excess energy of $2.463 \mathrm{eV}$ to populate the $v=9$ vibrational level [19].

The high-energy part of the $\mathrm{NO}^{+}$ion energy distribution observed with the HeI line has been interpreted by Brehm et al. [7] as the partition of the excess energy with respect to $14.194 \mathrm{eV}$ between the internal energy of $\mathrm{NO}^{+}\left(\mathrm{X}^{1} \Sigma^{+}\right)$and the kinetic energy of the fragments. $\mathrm{NO}^{+}\left(\mathrm{X}^{1} \Sigma^{+}\right)$is vibrationally distributed between $v=8$ and $v$ $=3$. By electroionization in the energy range 16.0-17.0 eV [1], the kinetic-energy versus appearance-energy diagram showed only $\mathrm{NO}^{+}\left(\mathrm{X}^{1} \Sigma^{+}, v=2\right)+\mathrm{N}\left({ }^{4} \mathrm{~S}\right)$ fragments with an increasing amount of kinetic energy. This discrepancy has been pointed out earlier [1]. As mentioned above, the $\mathrm{NO}^{+}$ion energy distribution observed by electroionization and with the HeI radiation on one hand and by photo-ionization with HeI radiation on the other are rather different.

The high-energy distribution peak at $200 \pm 50 \mathrm{meV}$ corresponds to about $630 \pm 150 \mathrm{meV}$ total kinetic 
energy carried by both $\mathrm{NO}^{+}$and $\mathrm{N}$ fragments. The $\mathrm{NO}^{+}$ions being produced by predissociation of the $\tilde{\mathrm{A}}^{2} \Sigma^{+}$state and the intensity enhancement giving rise to the observed ion energy distribution could be accounted for by the increase of relative intensity of a number of transitions as measured in the NeI photoelectron spectrum. The $\tilde{\mathrm{A}}$ ${ }^{2} \Sigma^{+}(2,0,0)$ with an enhancement ratio of $15: 1$ with respect to the HeI spectrum would produce $\mathrm{NO}^{+}\left(\mathrm{X}^{1} \Sigma^{+}, v=\right.$ 7) carrying $200 \mathrm{meV}$ kinetic energy. At higher ion energies, $\mathrm{NO}^{+}\left(\mathrm{X}^{1} \Sigma^{+}\right)$is produced in lower vibrational levels with increasing kinetic energy. For $700 \mathrm{meV}$ kinetic energy, $\mathrm{NO}^{+}$ions would be formed in the $\mathrm{X}^{1} \Sigma^{+}, v=1$ state.

The $\mathrm{N}_{2}^{+}$and $\mathrm{N}^{+}$ions, being produced only in the energy range of $\mathrm{N}_{2} \mathrm{O}^{+}\left(\widetilde{\mathrm{B}}^{2} \Pi\right.$ and/or $\left.\widetilde{\mathrm{C}}^{2} \Sigma^{+}\right)$states, are not observed when the NeI resonance lines are used.

\section{Acknowledgements}

This work has been performed under the auspices of the Action de Recherche Concertée (ARC) contract with the Belgian Government. We wish to thank the Fonds de la Recherche Fondamentale Collective (FRFC) for financial support.

\section{References}

[1] J.L. Olivier, R. Locht and J. Momigny, Chem. Phys. 68 (1982)201.

[2] J.L. Olivier, R. Locht and J. Momigny, Chem. Phys. 84 (1984) 295.

[3] J.A.R. Samson, Technique of vacuum UV spectroscopy (Wiley, New York, 1967).

[4] P. Natalis, Mém. Cl. Sc. Acad. Roy. Belg. XL1 (1973).

[5] R. Locht and J. Momigny, to be published.

[6] I. Lindau, J.C. Helmer and J. Uebbing, Rev. Sci. Instr. 44 (1973) 265.

[7] B. Brehm, R. Frey, A. Kusrler and J.H.D. Eland, Intern. J. Mass Spectrom. Ion Phys. 13 (1974) 251.

[8] J. Berkowitz and J.H.D. Eland, J. Chem. Phys. 67 (1977) 2740.

[9] R. Frey, B. Gotchev, W.B. Peatman, H. Pollak and E.W. Schlag, Chem. Phys. Letters 54 (1978) 411.

[10] I. Nenner, P.M. Guyon, T. Baer and T.R. Govers, J. Chem. Phys. 72 (1980) 6587.

[11] R.G. Orth and R.C. Dunbar, J. Chem. Phys. 66 (1977) 1616.

[12] P.M. Dehmer, J.L. Dehmer and W.A. Chupka, J. Chem. Phys. 73 (1980) 126.

[13] R. Locht and J. Momigny, to be published.

[14] P. Natalis, J.E. Collin, J. Delwiche, G. Caprace and M.J. Hubin-Franskin, J. Electron Spectry. 17 (1979) 421. 